\title{
Autopercepção da ansiedade: análise do cotidiano de um estudante
}

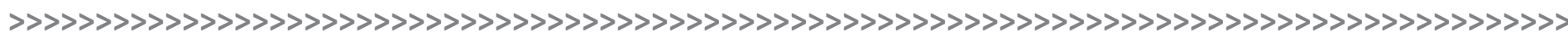

\author{
Laura Costa Fraga* \\ Daniel Giordani Vasques ${ }^{* *}$
}

\begin{abstract}
Resumo:
Esta pesquisa teve como objetivo analisar a autopercepção da ansiedade em um jovem estudante do Colégio de Aplicação da UFRGS. Ela foi realizada a partir da elaboração de um instrumento de pesquisa recordatório com anotações diárias, no qual o estudante anotava situações de ansiedade do seu dia. 0 diário foi elaborado com 16 páginas, contendo, em cada uma delas, uma tabela com nove perguntas. Ao todo, foram realizados 16 dias consecutivos de anotações. A pesquisa também foi realizada a partir de uma revisão bibliográfica de pesquisas que tratam sobre o tema de ansiedade como Salva (2008), Batista e Oliveira (2005), Castillo et al. (2000), dentre outros autores. Percebemos como resultados, que, durante os 16 dias de anotações o sujeito relatou ter passado por diferentes momentos de ansiedade no seu dia-a-dia, e que, a partir desta experiência, conseguiu buscar diferentes estratégias para amenizar os picos de ansiedade no seu cotidiano.
\end{abstract}

\section{Palavras-chave:}

Ansiedade. Autopercepção. Jovem. Diário.

\begin{abstract}
:
This research had the purpose of analyze the self perception of anxiety in a young student of Colégio de Aplicação of UFRGS. It was made from the construction of a research instrument of diary notes, in which the student wrote daily anxiety situations. The diary was built in 16 pages, and each one of them contained a table with nine questions, completing 16 consecutive days of notes. The research was also based from a bibliographic review of studies around anxiety as Salva (2008), Batista e Oliveira (2005), Castillo et al. (2000), among other authors. As results, we realize that in these days of notes, the subject said he has passed through differents anxiety moments in his daily life and that, from this experience, he has reached different strategies to minimize these anxiety peaks.
\end{abstract}

\section{Keywords:}

Anxiety. Self-perception. Young. Diary.

\section{Résumé:}

Cet article porte sur l'anxiété dans la vie quotidienne d'un jeune. L'objectif de cette étude est d'analyser les traits d'anxiété dans la vie quotidienne d'un jeune. La problématique est par conséquent la suivante: comment les traits d'anxiété étaient-ils perçus dans la vie quotidienne d'un jeune étudiant? Pour répondre à la problématique, une expérience incluant: une révision bibliographique et l'élaboration d'un journal intime sur les impres-

\footnotetext{
* $>$ Estudante do 8o ano do Ensino Fundamental do Colégio de Aplicação da Universidade Federal do Rio Grande do Sul (UFRGS). E-mail: laura03171623@ gmail.com.

** > Doutor em Ciências do Movimento Humano. Professor de Educação Física do Departamento de Expressão e Movimento do Colégio de Aplicação da UFRGS. E-mail: dgvasques@hotmail.com.
} 
sions de l'anxiété. Plusieurs raisons nous ont amené à porter la réflexion sur ce type de sujet, parmi elles l'intérêt de comprendre l'anxiété et sa présence massive dans notre société. De plus, le sujet s'identifie à certains traits de ce trouble. Les réponses récoltées montrent que pendant les 16 jours de notes que le sujet a signalé avoir passé pour différents moments d'anxiété dans sa vie quotidienne. Pour conclure cette expérience réussi à trouver des méthodes pour atténuer les pics d'anxiété dans leur vie quotidienne.

\section{Mots clés:}

Anxiété. Perception de soi. Jeunesse. Journal quotidien.

\section{Introdução}

Esta pesquisa foi desenvolvida por uma estudante do $8^{\circ}$ ano do Ensino Fundamental do Colégio de Aplicação da UFRGS durante a disciplina de Iniciação Científica no segundo semestre de 2019. Esse componente curricular obrigatório é composto de quatro horas semanais nas quais os estudantes, orientados por professores, são instigados a pesquisarem sobre temas/assuntos que os interessam e, dessa forma, experienciarem na práxis pedagógica o método científico. Dessa forma, o texto a seguir é o produto final da pesquisa construída por uma estudante e orientada por um professor da escola.

O meu assunto de pesquisa é a ansiedade, e, como recorte, escolhi o tema da autopercepção da ansiedade em um jovem aluno do Colégio de Aplicação da UFRGS. A ansiedade muitas vezes pode ser desenvolvida por causa do estresse, principalmente durante a fase da adolescência, onde os jovens têm diferentes emoções e sensações. Em algumas situações, essas emoções podem despertar situações de estresse, o que é uma grande ameaça ao desenvolvimento da ansiedade.

A pergunta de pesquisa desta investigação foi: "Como os traços de ansiedade foram percebidos no cotidiano de um jovem estudante?”, e as perguntas secundárias foram: “Em que hora do dia ocorrem os picos de ansiedade?"; "Em que situações?”; “O que ocorria antes e depois da ansiedade?"; e "Como o sujeito lidou com aquela situação?"

Esta pesquisa é resultante do Projeto Pixel do Colégio de Aplicação da UFRGS e, no oitavo ano, o tema central das investigações é "identidade", portanto, minha pesquisa relaciona-se com o tema, pois a ansiedade é um transtorno que modifica as sensações do sujeito e com isso influencia o seu modo de ser e agir, ou seja, compondo a identidade.

A justificativa desta investigação baseia-se no meu interesse em estudar sobre ansiedade, pois é um transtorno que atinge muitas pessoas na nossa sociedade, e também porque o sujeito pesquisado se identifica com alguns traços da ansiedade.

O que eu sabia, antes de realizar a investigação sobre o tema escolhido era que a ansiedade é um transtorno muito comum entre jovens e que, de diversas formas, afeta a vida dos sujeitos. Dessa forma, o objetivo desta investigação foi analisar traços de ansiedade no cotidiano de um jovem.

\section{Revisão bibliográfica}

Para explorar o tema que escolhi para a pesquisa, realizei dois movimentos: a leitura de livros selecionados na biblioteca do Colégio de Aplicação e a leitura de artigos científicos selecionados a partir de levantamento no Google Acadêmico. 


\section{Biblioteca}

O primeiro livro que li intitula-se O livro da psicologia, escrito por Colin et al. no ano de 2014. Os principais aprendizados com este material foram descobrir que o cérebro exerce muitas funções, e que o Freud é uma referência para a psicologia de atualmente.

O segundo livro que li intitula-se Dicionário da psicologia, escrito por Peter Stratton e Nicky Hayes, no ano de 1997. Os principais aprendizados com este material foram descobrir as formas que o cérebro pode interferir nas ações da ansiedade.

O terceiro livro que li intitula-se Tudo sobre drogas/ansiedade e stress, escrito por Tom Michelin, Alicia Bragg e John Cacciola, no ano de 1998. Os principais aprendizados com este material foram descobrir que o nosso estresse do dia a dia pode interferir no desenvolvimento da ansiedade.

\section{Artigos científicos}

O primeiro artigo científico que li intitula-se Narrativas da vivência juvenil feminina: histórias e poéticas produzidas por jovens de periferia urbana de Porto Alegre, escrito por Sueli Salva em sua tese de doutorado no ano de 2008. Os principais aprendizados com este artigo foram compreender que a escrita pode se tornar algo simbólico para uma pessoa e fazer com que ela conheça uma forma de expressão dos seus pensamentos.

O segundo artigo científico que li intitula-se Sintomas de ansiedade mais comuns em adolescentes, escrito por Marcos Antonio Batista e Sandra Maria da Silva Sales Oliveira, publicado na revista PSIC: Revista de Psicologia da Vetor Editora no ano de 2005. Os principais aprendizados com este artigo foram descobrir quais sintomas são mais predominantes no cotidiano de alguns jovens, sejam eles de qualquer gênero entre 14 e 18 anos.

O terceiro artigo científico que li intitula-se Transtornos de ansiedade, escrito por Ana Regina Castillo, Rogéria Recondo, Fernando Asbahr e Gisele Manfro, publicado na Revista Brasileira de Psiquiatria, no ano de 2000. Os principais aprendizados com este artigo foram descobrir que os transtornos que estão ligados à ansiedade podem interferir no comportamento do sujeito e também desenvolver outros medos.

\section{Aprendizados com as referências}

As principais questões que aprendi com esses autores e utilizei na minha pesquisa foram os temas que tratavam do cérebro, do comportamento mental e das características da ansiedade, pois para botar em prática o desenvolvimento da metodologia temos que saber o que vamos utilizar.

\section{Metodologia}

O roteiro básico da pesquisa foi organizado da seguinte forma: análise de artigos e livros, montagem do diário, análise do diário, conclusão da pesquisa e apresentação da pesquisa.

O tipo de pesquisa que escolhi realizar foi qualitativa na forma de um estudo de caso, porque os resultados são em sua maioria expressos em qualidade, em significado e também intensidade.

A pesquisa foi realizada como um estudo de caso, ou seja, as análises foram feitas com base das anotações de um sujeito, o qual percebia traços de ansiedade no seu cotidiano. 
Os estudos de caso são importantes para perceber em maior profundidade as características e comportamentos de um sujeito, os quais, apesar de não generalizáveis, podem ser considerados ao se analisar outros casos.

O sujeito analisado foi convidado a participar da pesquisa com base no critério de proximidade com a pesquisadora e por relatar apresentar traços de ansiedade. Ele possuía 14 anos de idade e estudava no $8^{\circ}$ ano do Ensino Fundamental quando os dados foram produzidos. Foram tomados cuidados éticos a fim de não revelar a sua identidade.

O instrumento de produção de dados foi elaborado da seguinte forma: o primeiro passo foi a construção de um diário autobiográfico, instrumento reconhecido (SALVA, 2008) para análises científicas sobre a autopercepção, o qual possuía 18 páginas. O segundo passo foi pensar o que o diário abordaria, ou seja, o que o sujeito iria anotar nele. Anotou-se em cada situação: dia, hora, dia da semana, o que levou o sujeito a ficar ansioso, o que o sujeito estava fazendo antes, se o sujeito demorou a perceber, se ele sentiu algo no corpo, como ele reagiu e se demorou a passar.

O terceiro passo foi pensar quantas anotações o sujeito iria fazer por dia, então decidimos que o sujeito iria descrever apenas um momento de maior ansiedade que teve no seu dia. Solicitou-se que o sujeito descrevesse no diário a situação de maior ansiedade de cada dia, o que resultou em 16 anotações.

Para analisar as informações produzidas, realizei um processo de leitura dos dados anotados do sujeito. A partir de uma quantificação das situações e ações realizadas pelo sujeito, buscou-se analisar situações repetitivas, bem como situações peculiares.

\section{Resultados}

Os resultados obtidos por meio das questões abordadas foram:

Durante os 16 dias de anotação, o indivíduo teve mais picos de ansiedade durante o período da manhã (ao todo, 12), à noite e à tarde foram registradas apenas duas vezes cada.

Uma primeira e importante análise do diário mostrou que as razões para ter ficado ansioso percebidas pelo indivíduo analisado foram de origem interna, interior, subjetiva, ou seja, estavam centradas no próprio sujeito. Assim, o sujeito alegou que a ansiedade foi por imaginar ou pensar em alguma situação em 13 das 16 vezes.

O sujeito estava fazendo, antes dos picos anotados de ansiedade, ações cotidianas e, na maioria de suas vezes, repetitivas, como mexer nas redes sociais, ouvir música, conversar e, até mesmo, estar em momentos de aula. Muitas dessas vezes, o sujeito estava conversando.

Em relação ao tempo levado para perceber os traços de ansiedade, o sujeito afirmou ter demorado a perceber a ansiedade em seis dias. Nas demais dez anotações, os traços foram percebidos rapidamente. Observou-se que, nas primeiras anotações, o sujeito demorou mais a perceber, o que nos levou a pensar que o próprio exercício de descrever os acontecimentos do cotidiano fez com que nas vezes seguintes elas fossem percebidas mais rapidamente.

Em todas as 16 anotações realizadas, o sujeito sentiu algo no corpo. Entre os sinais percebidos descritos, estavam: suar frio, falta de ar, tremor e chorar. Entre os sintomas, houve aceleração cardíaca e desconforto abdominal. Em todas as anotações realizadas, o sujeito relatou ter demorado para diminuir a ansiedade, ao todo 16 vezes. Esse tempo, por sua vez, não foi quantificado.

Ao todo, o sujeito encontrou diferentes formas para diminuir a ansiedade. Entre elas: tomar água, sair do local onde a ansiedade despertou, dormir, respirar fundo, distrair a mente, praticar yoga e também pensar em coisas positivas e boas. Como estratégia para amenizar a ansiedade, em algumas situações o sujeito procurou sair fisicamente do local, já em outras vezes, procurou apenas distrair a mente. 


\section{Considerações finais}

Assim como o projeto de pesquisa e a realização das etapas metodológicas são muito importantes, a chegada nas conclusões da pesquisa também o são. Assim, vou apresentar as considerações da minha pesquisa:

Durante toda a pesquisa, as leituras feitas foram de extrema importância para me auxiliar e me informar para o desenvolvimento do projeto.

A pesquisa foi construída em três partes: a primeira parte buscou listar uma série de questões a serem anotadas pelo sujeito investigado em uma situação de ansiedade diária. Esse processo de construção foi a consolidação do diário, ou seja, colocar as questões pensadas dentro do instrumento.

A segunda parte foi a aplicação do instrumento de pesquisa. Esse momento exigiu da pesquisadora a explicação detalhada do instrumento para o sujeito analisado, pois todas as respostas teriam que ser claras para que a pesquisadora pudesse entender a situação de ansiedade e conseguisse analisá-la.

A terceira parte envolveu analisar as anotações do sujeito e, nesse processo, procurei aproximações e distanciamentos entre as diferentes questões e situações. Esse processo envolveu analisar todas as repostas obtidas por meio do diário, fazer um levantamento e construir conclusões.

Como aprendizados além da investigação, pude ter uma experiência única que só por meio desta pesquisa ela foi realizada. Toda nova pesquisa nos traz novas perspectivas de ver o mundo, e agora, eu possuo uma nova perspectiva.

Como meus principais aprendizados, observei que, muitas vezes, a ansiedade pode se despertar em momentos inesperados; nem todas as pessoas que possuem ansiedade irão reagir da mesma maneira; a ansiedade pode afetar a mentalidade e também a produtividade da pessoa e como uma curiosidade temos de que cerca de 9,3\% da população brasileira sofre de ansiedade, segundo dado da Organização Mundial da Saúde (CHADE; PALHARES, 2017).

Esta pesquisa me fez ter mais empatia com as pessoas que sofrem de ansiedade na minha volta, pois nunca nos colocamos no lugar dos outros sem antes ter passado por alguma situação familiar.

Fazer pesquisa científica no colégio é importante, pois desperta o desejo de pesquisar sobre algo que para um sujeito é muito significante, nos faz ter mais contato com diferentes áreas do conhecimento e também nos deixa explorar coisas que nunca imaginamos que poderíamos descobrir.

\section{Referências}

BATISTA, Marcos Antonio; OLIVEIRA, Sandra Maria da Silva Sales. Sintomas de ansiedade mais comuns em adolescentes. PSIC: Revista de Psicologia da Vetor Editora, São Paulo, v. 6, n. 2, p. 43-50, jul./dez. 2005.

CASTILLO, Ana Regina; RECONDO, Rogéria; ASBAHR, Fernando; MANFRO, Gisele. Transtornos de ansiedade. Revista Brasileira de Psiquiatria, São Paulo, v. 22, p. 20-23, 2000. Suplemento 2.

CHADE, Jamil; PALHARES, Isabela. Brasil tem maior taxa de ansiedade o mundo, diz OMS. Estadão, São Paulo, 23 fev. 2017. Saúde. Disponível em: https://saude.estadao.com.br/noticias/ geral,brasil-tem-maior-taxa-de-transtorno-de-ansiedade-do-mundo-diz-oms,70001677247. Acesso em: 22 nov. 2019.

COLIN, Catherine et al. O livro da psicologia. 1. ed. São Paulo: Globo Editora, 2014.

MICHELIN, Tom; BRAGG, Alicia; CACCIOLA, John. Ansiedade e stress: tudo sobre drogas. Sâo Paulo: Nova Cultural, 1988. 
SALVA, Sueli. Narrativas da vivência juvenil feminina: histórias e poéticas produzidas por jovens de periferia urbana de Porto Alegre. 2008. Tese (Doutorado em Educação) - Universidade Federal do Rio Grande do Sul, Porto Alegre, 2008.

STRATTON, Peter; HAYES, Nicky (org.). Dicionário de psicologia. São Paulo: Pioneira, 1997. 